NIST Technical Note 1456

\title{
Operating Characteristics of the Proposed Sampling Plans for Testing Distribution Transformers
}

\author{
O. Petersons \\ K.L. Stricklett \\ C.R. Hagwood
}

NUT National Institute of Standards and Technology • Technology Administration • U.S. Department of Commerce 
NIST Technical Note 1456

\section{Operating Characteristics of the Proposed Sampling Plans for Testing Distribution Transformers}

O. Petersons

K.L. Stricklett

Quantum Electrical Metrology Division Electronics and Electrical Engineering Laboratory National Institute of Standards and Technology

Gaithersburg, MD 20899-8172

C.R. Hagwood

Statistical Engineering Division Information Technology Laboratory National Institute of Standards and Technology

Gaithersburg, MD 20899-8980

May 2004

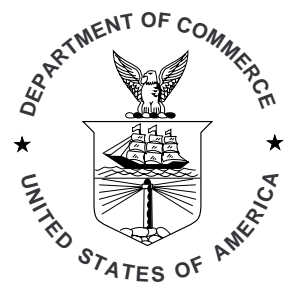

U.S. Department of Commerce Donald L. Evans, Secretary

Technology Administration Phillip J. Bond, Under Secretary for Technology

National Institute of Standards and Technology Arden L. Bement, Jr., Director 
Certain commercial entities, equipment, or materials may be identified in this document in order to describe an experimental procedure or concept adequately. Such identification is not intended to imply recommendation or endorsement by the National Institute of Standards and Technology, nor is it intended to imply that the entities, materials, or equipment are necessarily the best available for the purpose.

National Institute of Standards and Technology Technical Note 1456

Natl. Inst. Stand. Technol. Tech. Note 1456, 31 pages (May 2004) CODEN: NTNOEF

For sale by the Superintendent of Documents, U.S. Government Printing Office Internet: bookstore.gpo.gov—Phone: (202) 512-1800-Fax: (202) 512-2250 Mail: Stop SSOP, Washington, DC 20402-0001 


\title{
Bibliographic Information
}

\begin{abstract}
The sampling plans for efficiency testing contained in the Supplemental Notice of Proposed Rulemaking (SNOPR), Energy Conservation Program: Test Procedures for Distribution Transformers, are discussed. The proposed sampling plans test for compliance with standards for average energy efficiency. The SNOPR includes: a sampling plan for demonstration of compliance with a represented energy efficiency; criteria for substantiation of an alternative efficiency determination method; and a sampling plan for enforcement testing. Model calculations are presented that estimate the operating characteristics of the sampling plans, that is the probability of demonstrating compliance when testing a specific distribution of efficiencies.
\end{abstract}

\section{Keywords}

distribution transformers; efficiency testing; Energy Policy and Conservation Act; operating characteristics; sampling plan 


\section{Contents}

1 Introduction 1

2 EPCA guidelines 1

3 Industry practice 2

3.1 NEMA standards . . . . . . . . . . . . . . . . . . . . 2

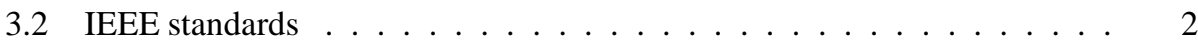

3.3 Comments . . . . . . . . . . . . . . . . . 2

4 Methods of analysis 3

4.1 Loss representation . . . . . . . . . . . . . . . . . . 4

5 Compliance testing 5

5.1 Statistical background . . . . . . . . . . . . . . . . . . 6

5.2 Operating characteristic . . . . . . . . . . . . . 7

6 AEDM substantiation $\quad 7$

7 Enforcement testing $\quad 8$

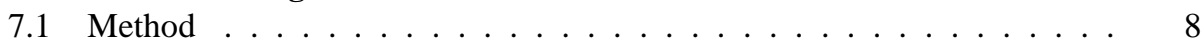

7.2 Results . . . . . . . . . . . . . . . . . . . . 9

8 Concluding remarks $\quad 10$

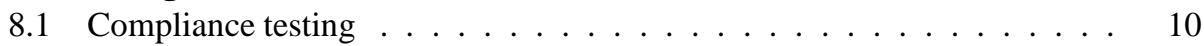

8.2 Enforcement testing . . . . . . . . . . . . . . . 10

9 Further information $\quad 10$

$\begin{array}{lr}\text { Appendix A: Compliance testing } & 21\end{array}$

Appendix B: Substantiation of an AEDM 22

Appendix C: Enforcement testing $\quad 23$ 


\section{List of Figures}

1. The operating characteristics of the sampling plan for compliance testing for an expanded uncertainty $(5 / \sqrt{n}) \%, n=1 \ldots \ldots \ldots$. . . . .

2. The operating characteristics of the sampling plan for compliance testing for an expanded uncertainty $(5 / \sqrt{n}) \%, n=5 \ldots \ldots \ldots$. . . . . . . . . . . . . . . . .

3. The operating characteristics of the sampling plan for compliance testing for an expanded uncertainty $(5 / \sqrt{n}) \%, n=10 \ldots \ldots \ldots$

4. The operating characteristics of the sampling plan for compliance testing for an expanded uncertainty $(8 / \sqrt{n}) \%, n=1 \ldots \ldots \ldots$. . . . .

5. The operating characteristics of the sampling plan for compliance testing for an expanded uncertainty $(8 / \sqrt{n}) \%, n=5 \ldots \ldots \ldots$. . . . .

6. The operating characteristics of the sampling plan for compliance testing for an expanded uncertainty $(8 / \sqrt{n}) \%, n=10 \ldots \ldots$. . . . . .

7. The operating characteristics of the Sampling Plan for Enforcement Testing for $m=20 \ldots \ldots \ldots \ldots \ldots \ldots \ldots$

8. The operating characteristics of the Sampling Plan for Enforcement Test-

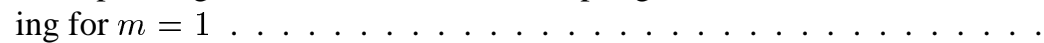

9. The average number of units tested under the Sampling Plan for Enforcement Testing . . . . . . . . . . . . . . . . . . 


\section{List of Tables}

1. NEMA Class 1 efficiency levels for liquid-filled distribution transformers. 3

2. NEMA Class 1 efficiency levels for dry-type distribution transformers. . . 4 


\section{Operating Characteristics of the Proposed Sampling Plans for Testing Distribution Transformers}

\section{Introduction}

This Technical Note provides analysis of the sampling plans for efficiency testing contained in the Supplemental Notice of Proposed Rulemaking (SNOPR), Energy Conservation Program: Test Procedures for Distribution Transformers [1]. The performance of the proposed sampling plans in demonstrating compliance with a represented efficiency is specifically addressed. The SNOPR was issued to resolve certain issues that arose during review of an earlier Notice of Proposed Rulemaking (NOPR) [2]. One issue being the properties of the proposed sampling plan for compliance testing. The sampling plan included in the earlier NOPR, which was modeled after the examples provided in $10 \mathrm{CFR}$ Part 430 [3], is discussed in an earlier report [4].

Under the provisions of the SNOPR, measurements of efficiency are contemplated for three purposes: 1) testing for compliance with a represented efficiency; 2) qualification of an Alternative Efficiency Determination Method (AEDM); and 3) enforcement testing. The objectives of testing in each of these circumstances differ in significant ways. Compliance testing is a one-time activity undertaken at the initiation of the program, upon enrollment into the program, or for qualification of a new product. The sampling plan for compliance testing is intended to ensure that the product in question meets or exceeds the represented efficiency. The SNOPR allows the use of an AEDM to determine the represented efficiency of distribution transformers, where an AEDM is a predictive model that is based on analysis of design and test data. An AEDM must, however, be substantiated before it may be used for this purpose. The criteria for substantiation of an AEDM provide a broad intercomparison of the performance predicted by the AEDM and test data. Finally, an enforcement action may be undertaken when the performance of a specific product or products is contested. Enforcement testing is one of a series of requirements under the Energy Policy and Conservation Act of 1975 (EPCA) as amended [5] during an enforcement action. The Sampling Plan for Enforcement Testing is designed to correctly determine whether a product is in compliance, while providing a low risk that a compliant product could fail by chance during an enforcement action.

The preparation of this report was undertaken at the request of the U.S. Department of Energy (DOE). This report is intended to supplement the materials presented in the SNOPR. While the authors believe the information presented here to be accurate and factual, this report is not a statement of the policies of the U.S. Department of Energy and must be re- garded only as commentary on the proposed sampling plans.

The remainder of this report is organized as follows: The general objectives of testing under EPCA are discussed in Section 2. Industry practice regarding efficiency performance is briefly reviewed in Section 3. The methods and model assumptions used in the evaluation of these sampling plans are presented in Section 4. Section 5 discusses the sampling plan for compliance testing; Section 6 discusses the criteria for substantiation of an AEDM; and the Sampling Plan for Enforcement Testing is presented in Section 7. Concluding remarks are provided in Section 8. Contact information for further information is provided in Section 9. For the convenience of the reader, each of the sampling plans are provided as appendices to this report: Appendix A contains the proposed sampling plan for compliance testing, Appendix B contains the criteria for substantiation of an AEDM, and the Sampling Plan for Enforcement Testing appears in Appendix C.

\section{EPCA guidelines}

The purpose of the EPCA legislation is stated in 42 U.S.C. $\S 6312(a)[6]:$

It is the purpose of this part to improve the efficiency of electric motors and pumps and certain other industrial equipment in order to conserve the energy resources of the Nation.

To this end, EPCA authorizes the establishment of energy performance standards that may specify energy efficiency or energy use for each covered product.

EPCA relies on a program of systematic testing to establish that energy performance standards are met. The objectives and limitations of testing under EPCA are stated in 42 U.S.C. $\S 6314(a)(2)$ :

Test procedures prescribed in accordance with this section shall be reasonably designed to produce test results which reflect energy efficiency, energy use, and estimated operating costs of a type of industrial equipment (or class thereof) during a representative average use cycle (as determined by the Secretary), and shall not be unduly burdensome to conduct. 
EPCA also addresses the represented energy performance of covered equipment in 42 U.S.C. $\S 6314(d)(1)$ :

...no manufacturer, distributor, retailer, or private labeler may make any representation-

(A) in writing (including a representation on a label), or

(B) in any broadcast advertisement,

respecting the energy consumption of such equipment or cost of energy consumed by such equipment, unless such equipment has been tested in accordance with such test procedure and such representation fairly discloses the results of such testing.

In the case of energy efficiency, the purpose of EPCA is met provided the average energy efficiency of each type of covered equipment 1 ) is not less than the EPCA energy efficiency standard for that product, and 2) is not less than the represented energy efficiency of that product. Energy efficiency must be demonstrated under EPCA through use of DOE test procedures. EPCA stipulates that such testing should not be unduly burdensome to conduct. Thus the two key criteria for evaluation of sampling plans for efficiency testing are: 1) the assurance provided that the average efficiency of that product meets or exceeds the represented efficiency, and 2) the burden placed on a manufacturer by testing under the plan.

\section{Industry practice}

Voluntary industry standards are typically developed by consensus among manufacturers, customers, and other stakeholders and are thus likely to describe technical capabilities that are broadly supported by that industry. A brief summary of references to the energy performance of distribution transformers in voluntary standards follows.

\subsection{NEMA standards}

Criteria for the energy performance of distribution transformers are included in two standards sanctioned by the National Electrical Manufacturers Association (NEMA): NEMA Standards Publication TP 1-2002, "Guide for Determining Energy Efficiency for Distribution Transformers" [7], and NEMA Standards Publication TP 2-1998 "Standard Test Method for Measuring the Energy Consumption of Distribution Transformers" [8].
NEMA TP 1: Section 4 of the NEMA TP 1 standard establishes energy efficiency levels for the NEMA class-1 designation. The minimum efficiencies for liquid-filled singleand three-phase transformers are tabulated in Table 4-1 of the TP 1 standard, and efficiency values for dry-type singleand three-phase transformers are tabulated in Table 4-2. Dry-type transformers are further delineated by voltage rating and basic insulation level (BIL): the standard provides efficiencies for low-voltage transformers and for mediumvoltage transformers having basic insulation levels less than or equal to $60 \mathrm{kV}$ and for basic insulation levels greater than $60 \mathrm{kV}$. The NEMA standard TP 1 tables are reproduced below in Tables 1 and 2. NEMA standard TP 1 states that the tabulated values are the "minimum efficiencies" for NEMA class 1 designation, which we interpret as "minimum [average] efficiencies."

NEMA TP 2: NEMA standard TP 2 stipulates that no individual transformer may exceed $108 \%$ of the rated loss under specific load conditions: The load condition for liquid-filled transformers and dry-type, medium-voltage transformers is $50 \%$ of the rated load; and the load condition for dry-type, low-voltage transformers is $35 \%$ of the rated load. Section 7 of the TP 2 standard provides a sampling plan for establishing compliance with the TP 1 efficiencies. Conformance with the TP 1 efficiencies is based on a weighted average of transformers manufactured in a period of $180 \mathrm{~d}$.

\subsection{IEEE standards}

Two standards sponsored by the Institute of Electrical and Electronics Engineers (IEEE) are also relevant to this discussion: IEEE Standard C57.12.00-2000, "General Requirements for Liquid-Immersed Distribution, Power and Regulating Transformers" [9]; and IEEE Standard C57.12.01-1998, "General Requirements for Dry-Type Distribution and Power Transformers, including those with Solid Case and/or Resin-Encapsulated Windings" [10].

The IEEE standards prescribe maximum loss limits for an individual transformer of $110 \%$ of the rated value for the no-load loss and $106 \%$ of the rated value for the total losses. Individual units having losses above these limits can be rejected.

\subsection{Comments}

Energy performance criteria for distribution transformers are provided in voluntary standards sponsored by NEMA and by IEEE. The NEMA standards establish minimum average efficiencies for distribution transformers and also set 
Table 1: NEMA Class 1 efficiency levels for liquid-filled distribution transformers [7].

\begin{tabular}{|c|c|c|c|}
\hline Reference Condition & \multicolumn{2}{|c|}{ Temperature } & $\%$ of Nameplate Load \\
\hline Load Loss & \multicolumn{2}{|c|}{$55^{\circ} \mathrm{C}$} & $50 \%$ \\
\hline No Load Loss & \multicolumn{2}{|c|}{$20^{\circ} \mathrm{C}$} & $50 \%$ \\
\hline & \multirow{2}{*}{\multicolumn{2}{|c|}{ Single Phase }} & Three Phase \\
\hline $\mathrm{kVA}$ & & $\mathrm{kVA}$ & Efficiency \\
\hline 10 & 98.4 & 15 & 98.1 \\
\hline 15 & 98.6 & 30 & 98.4 \\
\hline 25 & 98.7 & 45 & 98.6 \\
\hline 37.5 & 98.8 & 75 & 98.7 \\
\hline 50 & 98.9 & 112.5 & 98.8 \\
\hline 75 & 99.0 & 150 & 98.9 \\
\hline 100 & 99.0 & 225 & 99.0 \\
\hline 167 & 99.1 & 300 & 99.0 \\
\hline 250 & 99.2 & 500 & 99.1 \\
\hline 333 & 99.2 & 750 & 99.2 \\
\hline 500 & 99.3 & 1000 & 99.2 \\
\hline 667 & 99.4 & 1500 & 99.3 \\
\hline 833 & 99.4 & 2000 & 99.4 \\
\hline & & 2500 & 99.4 \\
\hline
\end{tabular}

limits on the maximum allowable loss power. The condition on the maximum loss power applies to individual transformers tested under specific load conditions. The IEEE standards also prescribe limits on the maximum loss power of an individual transformer. Since the measured loss power is directly related to the energy efficiency, these standards establish a tolerance on the measured efficiency of a single unit.

The minimum average efficiencies established in NEMA Standard TP 1 are stated as a percentage and are given to three significant figures, which implies that the resolution of energy efficiency measurements is at least $0.1 \%$. The limits on loss power are stated as a percentage of the rated loss power in both the NEMA and IEEE standards. The loss power is given to the nearest percent, which implies that the resolution of measured loss power is at least $1 \%$ of the rated loss.

The NEMA standard TP 2 imposes a maximum total loss limit of $108 \%$ of the rated value for liquid-filled transformers and for medium-voltage, dry-type transformers operated at $50 \%$ of the rated load. The same limit of $108 \%$ applies to low-voltage transformers operated at $35 \%$ of the rated load. IEEE standards limit the measured loss power to $106 \%$ of the rated loss power at full load and $110 \%$ of the rated value for no-load conditions. Under full load conditions the loss power is approximately four times larger than the no-load loss. Due to the reduced loading under NEMA standard TP 2 the no-load loss and the load loss are approximately equal, the maximum loss limits in both the IEEE and the NEMA standards are consistent.

\section{Methods of analysis}

Two figures-of-merit are considered and provide the basis for the evaluation of the sampling plans: 1) the operating characteristic, and 2) the testing burden. The operating characteristic of a sampling plan is the probability of demonstrating compliance when testing a specific distribution of efficiencies. This quantity provides an estimate of the probability or risk that an acceptable product could fail by chance or that an unacceptable product could pass by chance under that sampling plan. The second figure-of-merit, the testing burden, is the number of units tested. The minimum number of units to be tested is specified in the SNOPR for each sampling plan. However there are several exceptions to the recommended minimum sample size: the proposed sampling plans for compliance testing and enforcement testing both contain provisions for testing basic models that are produced in limited number; the Sampling Plan for Enforcement Testing tests whether the number of units tested is sufficient to support the conclusion and may require that additional units be tested; finally a manufacturer may elect to test units over and above the minimum required.

The sampling plans can be examined by means of model calculations. The model calculations presented assume that energy efficiency, and therefore loss power, is normally distributed with mean, $\mu$, and standard deviation, $\sigma$. The normal distribution is well known and may be evaluated numerically with high accuracy. Monte Carlo methods [11] can be adapted to evaluate sampling plans where the sample size is not fixed and are used in this document to estimate the testing burden of the Sampling Plan for Enforcement Testing. A discussion of the algorithms used to calculate the figuresof-merit can be found in [12-14]. 
Table 2: NEMA Class 1 efficiency levels for dry-type distribution transformers [7].

\begin{tabular}{|c|c|c|c|c|c|c|c|}
\hline \multicolumn{3}{|c|}{ Reference Condition } & \multicolumn{2}{|c|}{ Temperature } & \multicolumn{3}{|c|}{$\%$ of Nameplate Load } \\
\hline \multicolumn{3}{|c|}{ Low Voltage } & \multicolumn{2}{|c|}{$75^{\circ} \mathrm{C}$} & \multicolumn{3}{|c|}{$35 \%$} \\
\hline \multicolumn{3}{|c|}{ Medium Voltage } & \multicolumn{2}{|c|}{$75^{\circ} \mathrm{C}$} & \multicolumn{3}{|c|}{$50 \%$} \\
\hline \multicolumn{4}{|c|}{ Single Phase Efficiency } & \multicolumn{4}{|c|}{ Three Phase Efficiency } \\
\hline \multirow[t]{2}{*}{$\mathrm{kVA}$} & \multirow[t]{2}{*}{ Low Voltage } & \multicolumn{2}{|c|}{ Medium Voltage } & \multirow[t]{2}{*}{ kVA } & \multirow[t]{2}{*}{ Low Voltage } & \multicolumn{2}{|c|}{ Medium Voltage } \\
\hline & & $\leq 60 \mathrm{kV} \mathrm{BIL}$ & $>60 \mathrm{kV} \mathrm{BIL}$ & & & $\leq 60 \mathrm{kV} \mathrm{BIL}$ & $>60 \mathrm{kV} \mathrm{BIL}$ \\
\hline 15 & 97.7 & 97.6 & 97.6 & 15 & 97.0 & 96.8 & 96.8 \\
\hline 25 & 98.0 & 97.9 & 97.9 & 30 & 97.5 & 97.3 & 97.3 \\
\hline 37.5 & 98.2 & 98.1 & 98.1 & 45 & 97.7 & 97.6 & 97.6 \\
\hline 50 & 98.3 & 98.2 & 98.2 & 75 & 98.0 & 97.9 & 97.9 \\
\hline 75 & 98.5 & 98.4 & 98.4 & 112.5 & 98.2 & 98.1 & 98.1 \\
\hline 100 & 98.6 & 98.5 & 98.5 & 150 & 98.3 & 98.2 & 98.2 \\
\hline 167 & 98.7 & 98.8 & 98.7 & 225 & 98.5 & 98.4 & 98.4 \\
\hline 250 & 98.8 & 98.9 & 98.8 & 300 & 98.6 & 98.6 & 98.5 \\
\hline 333 & 98.9 & 99.0 & 98.9 & 500 & 98.7 & 98.8 & 98.7 \\
\hline 500 & - & 99.1 & 99.0 & 750 & 98.8 & 98.9 & 98.8 \\
\hline 667 & - & 99.2 & 99.0 & 1000 & 98.9 & 99.0 & 98.9 \\
\hline \multirow[t]{3}{*}{833} & - & 99.2 & 99.1 & 1500 & - & 99.1 & 99.0 \\
\hline & & & & 2000 & - & 99.2 & 99.0 \\
\hline & & & & 2500 & - & 99.2 & 99.1 \\
\hline
\end{tabular}

\subsection{Loss representation}

Transformer energy efficiency, $\eta$, is determined by two quantities: the output power, $P_{o}$, and the loss power, $P_{l}$. Expressed as a percentage, transformer efficiency is given by the following equation:

$$
\eta=\frac{P_{o}}{P_{o}+P_{l}} \times 100 .
$$

The practice of the transformer industry is to measure transformer loss power and to perform intermediate computations in terms of loss power. Transformer energy efficiency is typically calculated for purposes of final validation and is based on the measured loss power.

The energy performance of distribution transformers is stated in the SNOPR in terms of energy efficiency. We have chosen, for this analysis however, to represent transformer energy performance in terms of energy use or loss power. The loss representation of energy performance has the advantage of being independent of efficiency; figures-of-merit can thus be summarized globally rather than on a case-bycase basis for each energy efficiency. This representation also provides direct comparison with the tolerance on the measured losses specified in the NEMA and IEEE standards.

In the discussion that follows, the figures-of-merit are represented by contour plots, see Fig. 1, for example. The coordinates for these plots are the normalized average loss and the normalized standard deviation of the population. The average loss and standard deviation are normalized to the represented loss and are given as a percentage of the represented loss. In all cases, the represented loss corresponds to $100 \%$ on the average loss axis.
The NEMA and IEEE standards both place conditions on the maximum allowable loss power of a single unit. It may be inferred then that there is some risk that an individual transformer may have exceptionally high loss power and may be rejected on that basis. Rejecting a distribution transformer during final validation is costly and a manufacture must limit such rejections. Statements made during the public hearing on the earlier NOPR [15] suggest that the maximum loss limits in the NEMA and IEEE standards correspond to approximately three standard deviations for at least some transformers and manufacturers, which implies that the rate of rejection is on the order of one per thousand. Assuming that distribution transformers are designed to meet the represented loss power on average yields a standard deviation of approximately $2.7 \%$ when using the figure of $108 \%$ from NEMA standard TP 2. A higher value of $4.0 \%$ for the standard deviation was mentioned during the public hearing. A subsequent letter from NEMA [16] also cites the $4.0 \%$ figure for the standard deviation. For the larger standard deviation, the design point would have to be set below the represented loss in order to maintain a low rate of rejection. The distribution of loss power would likely differ between manufacturers and basic models. Indeed a statement made at the public hearing indicated that the data on product variability maintained by manufacturers are proprietary. We conclude that the population standard deviation of the loss power is likely to range in value between approximately $2.7-4.0 \%$. The sampling plans are tailored to this range of values. 


\section{Compliance testing}

The sampling plan for compliance testing is contained in $\S 432.12(\mathrm{~b})(2)$ of the proposed rule. For the convenience of the reader it has been included as Appendix A to this report.

The proposed rule groups distribution transformers into $b a$ sic models for compliance testing, where basic model is fully defined in $\$ 432.10$. For the purposes of this discussion, basic model will refer to distribution transformers having energy efficiencies that are nominally equivalent.

The sampling plans for compliance testing contained in 10 CFR Part 430 and Part 431 are tailored to the characteristics of the specific covered products $[4,12,13]$. Distribution transformers as a product have characteristics that differ substantially from the products covered under 10 CFR Part 430 and Part 431: in particular, some basic models are produced in very limited number, indeed, a basic model as defined in $\S 432.10$ may describe a single transformer.

The sampling plans for compliance testing provided in 10 CFR Part 430 are based on the $t$-test in statistics. As discussed below, the $t$-test presents difficulties when testing small samples: For small sample sizes the value of the $t$ statistic is large, resulting in broad confidence intervals and low precision in the determination of the population mean from the sample. The $t$-test cannot be used to evaluate the results of a single test.

The $z$-test allows testing of small samples, including samples of one. Test methods based on the $z$-test can be employed if the population standard deviation is known. Since a manufacturer will likely know the range of standard deviations from test results obtained on similar transformers, the $z$-test may be appropriately applied to compliance testing.

EPCA energy performance standards may place a lower bound on the average efficiency or an upper bound on the average energy use of a covered product. The proposed rule places a condition on the mean efficiency of the sample in a demonstration of compliance with a represented efficiency. To emphasize the salient features of the proposed sampling plan for compliance testing, we paraphrase the sampling plan as follows:

A sample of not fewer than five units shall be tested whenever possible. However, if fewer than five units are produced in a period of $180 \mathrm{~d}$, then each unit produced in a period of $180 \mathrm{~d}$ shall be tested. Compliance with a represented average efficiency is demonstrated provided:

The average efficiency of the sample is not less than the represented efficiency minus an expanded uncertainty [17].
The criterion for a demonstration on compliance can be stated as a condition on the average efficiency of the sample or as a condition on the average energy use of the sample. A compliance demonstration can be performed on the basis of energu use by comparing the measured average loss power of a sample with the represented loss calculated from the represented efficiency.

Criterion for efficiency testing: Stated in terms of efficiency, the condition for compliance demonstration is

$$
\bar{X} \geq \frac{100}{1+\left(1+\frac{0.05}{\sqrt{n}}\right)\left(\frac{100}{R E}-1\right)},
$$

where $\bar{X}$ is the mean efficiency of a sample in percent, $R E$ is the represented efficiency of the basic model in percent, and $n$ is the number of units tested. Equation (2) is provided in the proposed rule as the condition on the mean efficiency of the sample required for a demonstration of compliance with a represented efficiency.

In the process of determining compliance, the transformer no-load and load losses are measured, the measurement data are adjusted to reference conditions and loading levels, the efficiency of each transformer and the average efficiency of the sample are calculated, all according to the test procedure proposed in the SNOPR. The resulting sample average efficiency is compared with the represented efficiency of the standard using eq. (2) to determine the compliance status of the basic model. Efficiency is used as the measure of energy consumption of distribution transformers because it combines the effects of both the no-load and load losses.

Criterion for energy use testing: The mean loss power of the sample must not exceed the represented loss plus an expanded uncertainty. The expanded uncertainty proposed is $5 \%$ of the represented loss scaled by a factor of $1 / \sqrt{n}$ where $n$ is the number of units in the sample. The condition on the sample mean efficiency stipulated in the proposed rule is equivalent to the following condition on the mean loss power of the sample:

$$
\bar{X}_{l} \leq R L\left(1+\frac{0.05}{\sqrt{n}}\right)
$$

where $\bar{X}_{l}$ is the mean loss power of the sample in watts and $R L$ is the represented loss power of the basic model in watts. Condition (3), expressed as a percentage of the represented loss, is given by

$$
\bar{X}_{l} \leq\left(100+\frac{5}{\sqrt{n}}\right)
$$

where $\bar{X}_{l}$ is the normalized mean loss power of the sample in percent. 


\subsection{Statistical background}

Finding a confidence interval on a mean and testing the mean of a population from a sample are well known problems in statistical engineering [18].

The sampling plan for compliance testing is a test on a mean; and an estimate of the mean loss power of the population is obtained by a random sample

$$
\bar{X}_{l}=\frac{1}{n} \sum_{i=1}^{n} X_{i}
$$

where $X_{i}$ is the measured loss power of unit $i$, and $n$ is the number of units tested. The uncertainty in this estimate depends on three factors: 1) the size of the sample, that is, the number of transformers tested, 2) the underlying variability in the population, and 3) the measurement uncertainty.

The condition for compliance with a represented loss is,

$$
\mu_{l} \leq R L
$$

where $\mu_{l}$ is the average loss power of the population and $R L$ is the represented loss power. In a test of compliance with a represented loss power, it is assumed by hypothesis that the mean loss power of the population is not greater than the represented loss power. This hypothesis is not rejected, provided the mean loss power of a random sample is not greater than the represented loss plus an expanded uncertainty. In a statistical test there is some probability of concluding falsely that an acceptable product is not compliant or that an unacceptable product is compliant. The form of the expanded uncertainty influences the statistical confidence, that is, the probability that the mean loss power of the population actually satisfies condition (6).

Two cases are considered: 1) the variance of the population, $\sigma_{l}^{2}$, is unknown and must be estimated from the sample; and 2) the variance is known.

Unknown variance: When the variance is not known, the population standard deviation, $\sigma_{l}$, must be estimated from the sample data. The sample standard deviation,

$$
S=\sqrt{\frac{\sum_{i=1}^{n}\left(X_{i}-\bar{X}_{l}\right)^{2}}{n-1}},
$$

provides an estimate of the population standard deviation; and the standard error of the mean,

$$
S E\left(\bar{X}_{l}\right)=\frac{S}{\sqrt{n}},
$$

provides an estimate of the standard deviation of the mean for a sample of $n$ units. For a normal distribution with mean $\mu_{l} ;$ the ratio,

$$
t=\frac{\bar{X}_{l}-\mu_{l}}{S E\left(\bar{X}_{l}\right)},
$$

is distributed according to a probability density function that is known in statistics literature as the $t$-distribution. $t$ may range in value from minus infinity to infinity, and the density function, $f(t)$, is defined such that

$$
\int_{-\infty}^{\infty} f(t) d t=1
$$

The $a$ quantile, $t_{a}$, is defined such that the integral of density from minus infinity to $t_{a}$ equals $a$,

$$
\begin{aligned}
\int_{-\infty}^{t_{a}} f(t) d t & =a \\
& =\operatorname{Pr}\left[t \leq t_{a}\right]
\end{aligned}
$$

where $\operatorname{Pr}\left[t \leq t_{a}\right]$ is the probability that $t$ will assume values less than or equal to $t_{a}$. $(1-a)$ is then the probability that $t$ will assume values greater than $t_{a}, \operatorname{Pr}\left[t>t_{a}\right]=(1-a)$.

Equation (9) may be rearranged to provide the following expression for the mean of the sample:

$$
\bar{X}_{l}=\mu_{l}+t S E\left(\bar{X}_{l}\right),
$$

which suggests the condition,

$$
\bar{X}_{l} \leq R L+t_{a} S E\left(\bar{X}_{l}\right)
$$

on the mean of the sample in a demonstration of compliance with a represented loss power. The value of $t_{a}$ is associated with a specific sample size and statistical confidence $a$. Values of $t_{a}$ are readily available and are included in many references on statistics [19].

Known variance: The standard deviation of the sample mean for a sample of $n$ units is $\sigma_{l} / \sqrt{n}$, where $\sigma_{l}$ is the population standard deviation. The standardized random variable, $z$, is realized as the ratio,

$$
z=\frac{\bar{X}_{l}-\mu_{l}}{\sigma_{l} / \sqrt{n}},
$$

where $z$ may assume values from minus infinity to infinity and is normally distributed with mean 0 . The standard normal density function, $\phi(z)$, is defined such that

$$
\int_{-\infty}^{\infty} \phi(z) d z=1 .
$$

The $a$ quantile, $z_{a}$, is defined such that the integral of standard normal density from minus infinity to $z_{a}$ equals $a$,

$$
\begin{aligned}
\int_{-\infty}^{z_{a}} \phi(z) d z & =a \\
& =\operatorname{Pr}\left[z \leq z_{a}\right]
\end{aligned}
$$


where $\operatorname{Pr}\left[z \leq z_{a}\right]$ is the probability that $z$ will assume values less than or equal to $z_{a}$. $(1-a)$ is then the probability that $z$ will assume values greater than $z_{a}, \operatorname{Pr}\left[z>z_{a}\right]=$ $(1-a)$.

Equation (14) may be rearranged to provide an expression for the mean of the sample

$$
\bar{X}_{l}=\mu_{l}+z \frac{\sigma_{l}}{\sqrt{n}},
$$

which suggests the condition,

$$
\bar{X}_{l} \leq R L+z_{a} \frac{\sigma_{l}}{\sqrt{n}},
$$

on the mean of the sample for compliance with a represented loss with confidence $a$.

Conditions (13) and (18) for the $t$-test and the $z$-test, respectively, are similar. Indeed, for $n$ greater than 30 , the two tests yield essentially identical results. In a $z$-test the standard deviation of the population, $\sigma_{l}$, is known from previous tests, whereas in a $t$-test the standard deviation of the population is estimated from the sample data. Because the variability is estimated from the sample in the $t$-test, the confidence limits are broader. It should be noted that the sample standard deviation (7) is not defined for $n=1$. The value of $t$ is thus not defined, and the $t$-test cannot be used for samples of one. The z-test satisfies a key criterion for testing distribution transformers: The $z$-test performs well when testing small samples.

\subsection{Operating characteristic}

The operating characteristic is a function of the mean, $\mu_{l}$, and the standard deviation, $\sigma_{l}$, of the loss power. Using eq. (3), the operating characteristic is given by

$$
\begin{aligned}
p\left(\mu_{l}, \sigma_{l}\right) & =\operatorname{Pr}\left[\bar{X}_{l} \leq R L\left(1+\frac{0.05}{\sqrt{n}}\right)\right] \\
& =\operatorname{Pr}\left[\frac{\bar{X}_{l}-\mu_{l}}{\sigma_{l} / \sqrt{n}} \leq \frac{R L-\mu_{l}}{\sigma_{l} / \sqrt{n}}+\frac{0.05 R L}{\sigma_{l}}\right] \\
& =\Phi\left(\frac{R L-\mu_{l}}{\sigma_{l} / \sqrt{n}}+\frac{0.05 R L}{\sigma_{l}}\right)
\end{aligned}
$$

where $\Phi(z)$ is the cumulative distribution function of $z$. The level curves of the operating characteristic function, $a=p\left(\mu_{l}, \sigma_{l}\right), 0<a<1$, determine what sampling design parameters $\mu_{l}$ and $\sigma_{l}$ produce compliance with the stated probability $a$.

The operating characteristics of the proposed sampling plan for compliance testing are summarized graphically in Figs. 1-3. The data shown in the figures are for an expanded uncertainty of $(5 / \sqrt{n}) \%$ and for sample sizes of $n=1,5$ and 10, respectively. Level curves are plotted in the figures for $a=0.999,0.99,0.90,0.75,0.50,0.25,0.10,0.01$, and 0.001 , for $\mu_{l}$ ranging from $95-110 \%$ and $\sigma_{l}$ ranging from $0-6 \%$.

The level curves turn out to be straight lines, as can be seen by noting that $a=p\left(\mu_{l}, \sigma_{l}\right)$ implies

$$
a=\Phi\left(\frac{R L-\mu_{l}}{\sigma_{l} / \sqrt{n}}+\frac{0.05 R L}{\sigma_{l}}\right) .
$$

The points $\left(\mu_{l}, \sigma_{l}\right)$ that satisfy this equation are

$$
\begin{aligned}
z_{a} & =\frac{R L-\mu_{l}}{\sigma_{l} / \sqrt{n}}+\frac{0.05 R L}{\sigma_{l}}, \text { or } \\
\sigma & =\frac{R L-\mu_{l}}{z_{a} / \sqrt{n}}+\frac{0.05 R L}{z_{a}} .
\end{aligned}
$$

The represented loss power is normalized to $100 \%$ in the figures. Thus the region of compliance with a represented loss power is for $\mu_{l} \leq 100 \%$ and the region of noncompliance is for $\mu_{l}>100 \%$. Equation (3) implies that a basic model manufactured with losses $5 / \sqrt{n} \%$ above the represented value, that is, $\mu_{l}=100+5 / \sqrt{n} \%$, will have 0.5 probability of demonstrating compliance for all standard deviations. Indeed substituting $\mu_{l}=R L(1+0.05 / \sqrt{n})$ into eq. (19) gives $\Phi(0)=0.50$. Hence, the 0.50 contour is a vertical line intersecting the horizontal axis at $100+5 / \sqrt{n} \%$. The other level curves converge to the same point on the horizontal axis, and the slope of each level curve is $\left(\sqrt{n} / z_{a}\right)$.

The value of the expanded uncertainty influences the operating characteristics. The operating characteristics for an expanded uncertainty of $(8 / \sqrt{n}) \%$ are shown in Figs. 4-6 for comparison. The data shown are again for samples of $n=1$, 5 and 10.

\section{AEDM substantiation}

The SNOPR contemplates the use of an Alternative Efficiency Determination Method (AEDM) to determine the represented efficiency of a basic model. The SNOPR stipulates, however, that a manufacturer must substantiate the accuracy and reliability of an AEDM before it can be used as the basis for the represented efficiency. The criteria for substantiation of an AEDM are provided in $\S 432.12$ (a)(3) of the proposed 10 CFR Part 432. The text of the proposal is provided in Appendix B to this report.

An AEDM is substantiated by comparison of the predicted loss power and the measured loss power. The SNOPR places several conditions on this comparison: The predicted loss power must be compared with the measured loss power for not fewer than five basic models; not fewer than five units 
must be tested for each basic model that is selected for testing; and the predicted loss power must be within plus or minus $5 \%$ of the mean loss power of the sample for each basic model tested. Specific criteria are provided in $\$ 432.12(\mathrm{~b})(1)$ for the selection of basic models for testing that are intended to provide a broad sample of the basic models manufactured.

The SNOPR also places a condition on the global behavior of the AEDM: The predicted loss power expressed as a percentage of the mean loss power of the sample is calculated for each basic model tested. The predicted loss power averaged over all basic models tested must not be less than $97 \%$ nor greater than $103 \%$.

\section{Enforcement testing}

The Sampling Plan for Enforcement Testing proposed for distribution transformers is provided in Appendix B to Subpart B of Part 432. For the convenience of the reader, the text of the proposed sampling plan is included in Appendix C. The proposed sampling plan is similar to that provided in 10 CFR Part 430 and in Part 431. Part 430, however, contains standards for both efficiency and energy consumption and the Sampling Plan for Enforcement Testing included there is very general. Since, in the case of transformers, only standards for efficiency are contemplated, the proposed sampling plan is simplified somewhat from the Part 430 plan to include only efficiency testing.

The proposed Sampling Plan for Enforcement Testing is based on a well established statistical method, which is due to C. Stein [20], for obtaining a confidence interval on a mean. A discussion of this procedure can be found in Bickel and Doksum [18], for example. The procedure is based on a $t$-test. The $t$-test is well suited to this application as it is known to be insensitive to departures from the assumption of normality: The $t$-test is a test on a mean, which is an average of independent values obtained by a random sample. Since sums of arbitrary, independent random values tend to have a distribution that is almost normal, the $t$-test is not strongly influenced by the exact form of the underlying distribution.

Since test results obtained during an enforcement action may recommend that adverse actions be taken against a manufacturer-such actions may include, for example, relabeling of specific products, the cessation of distribution and sale of certain basic models, and/or the assessment of fines - the risk to a manufacturer of a false determination of non-compliance during enforcement testing is set, by design, to a negligible level. The proposed Sampling Plan for Enforcement Testing is based on a $97.5 \%$ statistical confidence, and thus the risk of a chance false determination of non-compliance is not greater than $2.5 \%$.

\subsection{Method}

The discussion of the proposed Sampling Plan for Enforcement Testing is again presented in terms of loss power rather than efficiency. The conditions provided here on loss power are equivalent to the conditions on efficiency provided in the proposed sampling plan.

An estimate of the mean loss power of the population, $\mu_{l}$, is obtained by a random sample,

$$
\bar{X}_{l}=\frac{1}{n} \sum_{i=1}^{n} X_{i}
$$

where $X_{i}$ is the measured loss power of unit $i$, and $n$ is the number of tests conducted.

The sample standard deviation,

$$
S=\sqrt{\frac{\sum_{i=1}^{n}\left(X_{i}-\bar{X}_{l}\right)^{2}}{n-1}}
$$

provides an estimate of the population standard deviation, $\sigma_{l}$; and the standard error of the mean,

$$
S E(\bar{X})=\frac{S}{\sqrt{n}},
$$

provides an estimate of the standard deviation of the mean for samples of $n$ tests. For a normal distribution with mean $\mu_{l}$; the ratio,

$$
t=\frac{\bar{X}_{l}-\mu_{l}}{S E\left(\bar{X}_{l}\right)},
$$

is distributed according to a probability density function that is known in the statistics literature as the $t$-distribution.

Equation (25) may be rearranged to provide an expression for the mean of the sample as follows:

$$
\bar{X}_{l}=\mu_{l}+t_{a} S E\left(\bar{X}_{l}\right)
$$

where the value of $t_{a}$ is associated with a specific sample size and statistical confidence $a$. Values of $t_{a}$ are readily available and are included in many references on statistics [19].

In a test of compliance with a represented loss power, $R L$, we assume, by hypothesis, that the units to be tested are drawn from a population of transformers for which the mean loss power is not greater than the represented loss power. If $t_{a}$ is the 97.5 percentile of the $t$-distribution for $n-1$ degrees of freedom, then the probability of obtaining a mean sample loss power, $\bar{X}_{l}$, such that

$$
\bar{X}_{l} \leq R L+t_{a} S E\left(\bar{X}_{l}\right)
$$


is not less than $97.5 \%$. This procedure recommends an upper control limit,

$$
U C L=R L+t_{a} S E\left(\bar{X}_{l}\right) .
$$

To apply this method, a random sample is tested and the mean and standard error of the mean are calculated. Based on the number of tests conducted and the desired confidence interval, the appropriate $t$-value is selected and the upper control limit is calculated. For example, $97.5 \%$ confidence and a sample size of five tests yields a $t$-value of 2.78 for four degrees of freedom. Provided the mean loss power obtained from the random sample is not greater than the upper control limit, as defined by eq. (28), we may assert with confidence of at least $97.5 \%$ that the mean loss power of the population is not greater than the represented value.

In a statistical test there is some probability of incorrectly concluding that the product is not compliant. By design, the probability that the mean loss power for a random sample drawn from a compliant population of transformers would fall above the upper control limit, hence, the risk of incorrectly concluding that the basic model is not compliant, is not greater than $2.5 \%$.

The standard deviation of the population is estimated from a random sample, and there is some probability that the sample standard deviation may be exceptionally large and that the upper control limit may be set, by chance, to a high value. This circumstance may be avoided by placing a tolerance on the standard error of the mean, $S E\left(\bar{X}_{l}\right)$. The proposed sampling plan imposes the following condition on the standard error of the mean: The $97.5 \%$ confidence interval on the mean loss power must not exceed $5 \%$, that is,

$$
t_{a} S E\left(\bar{X}_{l}\right) \leq 5,
$$

where $t_{a}$ is selected for a $97.5 \%$ confidence interval and an initial sample of $n_{1}$ tests. An expression for the number of units to be tested, $n$, is obtained from eqs. (24) and (29):

$$
n \geq\left(\frac{t_{a} S}{5}\right)^{2} .
$$

The proposed sampling plan requires further testing if the number of tests conducted initially, $n_{1}$, is less than the minimum value of $n$ from eq. (30).

As indicated earlier, some basic models of distribution transformers may be produced in limited numbers. Two features of the proposed Sampling Plan for Enforcement Testing are provided to allow for tests of small samples: 1) a sample size discount is included in the calculation of the upper control limit, and 2) a minimum number of tests rather than a minimum number of units tested is specified.

The sample size discount, $S S D$, in the proposed Sampling Plan for Enforcement Testing is modeled after the sampling plan for compliance testing. The sample size discount is given by:

$$
S S D=100+\frac{5}{\sqrt{m}},
$$

where $m$ is the number of units selected for testing. The sampling plan recommends that 20 units be selected for testing, however, it allows testing when fewer than 20 units are selected for testing. Indeed, the value of $m$ may range between 1 and 20. The sample size discount is included in the calculation of the upper control limit,

$$
U C L=S S D+t_{a} S E\left(\bar{X}_{l}\right) .
$$

It should be noted that the sample size discount proposed for purposes of enforcement testing is consistent with the control limit (4) proposed for compliance testing.

The proposed sampling plan differentiates between the number of units selected for testing, $m$, and the number of tests conducted, $n$. Criteria for establishing the number of tests initially conducted are provided in $\S 432.13(a)(5)$ through (8). These criteria provide that a single unit would be tested four times, two units would be tested twice each, three units would be tested twice each, and four or more units would be tested once each. The value of $t$ selected is based on the number of tests initially conducted rather than the number of units initially tested.

\subsection{Results}

The operating characteristics of the proposed Sampling Plan for Enforcement Testing are shown in Figs. 7 and 8. The data shown in Fig. 7 are for a $97.5 \%$ statistical confidence, 20 units selected for testing and five initial tests. Level curves are plotted in the figures for $a=0.999,0.99,0.975$, $0.90,0.75,0.50,0.25,0.10,0.01$, and 0.001 , for $\mu_{l}$ ranging from $95-110 \%$ and $\sigma_{l}$ ranging from $0-6 \%$. The results of two computational methods are presented: numerical computations and Monte Carlo simulations [4]. The continuous level lines indicate the numerical results and the results of Monte Carlo calculations are indicated by the irregular lines. The two methods yield consistent results. The data shown in Fig. 8 are for the case where one unit has beeb selected for testing, that is, $m=1$. It may be noted that the $97.5 \%$ contour lies along the $(100+5 / \sqrt{m}) \%$ loss line in each of the figures, and that the risk of a false outcome is therefore independent of the variance for $(100+5 / \sqrt{m}) \%$ average loss.

Data indicating the estimated testing burden, that is, the average number of units tested, are shown in Fig. 9. The data shown are obtained by Monte Carlo calculations for a $97.5 \%$ statistical confidence, 20 units selected for testing, and five initial tests. Level curves are plotted in the figure 
for $n=5,6,7,8$, and 9 , for $\mu_{l}$ ranging from 95-110\% and $\sigma_{l}$ ranging from $0-6 \%$. These data suggest that six tests would likely be required during an enforcement action.

\section{Concluding remarks}

\subsection{Compliance testing}

The sampling plan for compliance testing contained in the earlier NOPR [2] was modeled after examples provided in 10 CFR Part 430. That sampling plan required the average efficiency of a sample to be not less than the represented value and also placed a condition on the lower confidence limit of the efficiency. The probability of demonstrating compliance under such a plan is thus not greater than 0.5 when testing a product having a population mean efficiency that is equal to the rated value. The sampling plan contained in the earlier NOPR provides very high assurance that the product meets or exceeds the represented efficiency: under that plan, in order to provide a reasonable likelihood of succeeding during a test of compliance with a represented efficiency the energy performance of the product must exceed the represented value. Comments were made during the public hearing [15] to suggest that distribution transformers are manufactured to meet the rated efficiency on average and that significant over design is inconsistent with industry practice. The sampling plan for compliance testing contained the SNOPR is designed to provide a higher probability of demonstrating compliance than afforded under the earlier NOPR when a product with energy performance at or near the represented value is tested.

The operating characteristics of the proposed sampling plan depend on the numerical value and the functional form of the expanded uncertainty. The specific numerical value of $(5 / \sqrt{n}) \%$ for the expanded uncertainty provides a reasonable likelihood that a product with average energy performance at the represented value would succeed during a test of compliance and yet not afford a significant probability of success when the product is not compliant. Although the sampling plan for compliance testing contained the SNOPR provides a higher probability of demonstrating compliance than afforded under the earlier NOPR, the proposed sampling plan still encourages average performance over and above the represented efficiency.

The proposed sampling plan allows testing of large and small samples, including a sample of one unit. The standard deviation of the mean of a sample scales as $1 / \sqrt{n}$, where $n$ is the size of the sample. The scaling factor $1 / \sqrt{n}$ included in the expanded uncertainty thus removes any bias due to sample size. For products manufactured at the represented value, the probability of demonstrating compliance is independent of sample size.

\subsection{Enforcement testing}

The Sampling Plan for Enforcement Testing proposed for 10 CFR Part 432 is based on statistical methods that are widely used and well documented. The factors that influence the operating characteristics include: 1) the size of the initial sample, 2) the statistical confidence, and 3) the tolerance set on the standard error. The sampling plan is robust, in that it is a test on the mean and that it is not highly dependent on the exact form of the underlying distribution. The sampling plan is designed to protect the interests of the manufacturer, in that the risk of a false outcome against a manufacturer may be limited to an acceptable level.

\section{Further information}

For information on the test procedure rulemaking for distribution transformers or on EPCA legislation contact:

Cyrus Nasseri

U.S. Department of Energy

Energy Efficiency and Renewable Energy

Building Technologies

Mail Station EE-2J

1000 Independence Avenue, SW

Washington, DC 20585-0121

202-586-9138

Cyrus.Nasseri@ee.doe.gov

For information on this report contact:

Oskars Petersons

National Institute of Standards and Technology

100 Bureau Drive, MS-8172

Gaithersburg, MD 20899-8172

oskars.petersons@nist.gov

Ken Stricklett

National Institute of Standards and Technology

100 Bureau Drive, MS-8172

Gaithersburg, MD 20899-8172

301-975-3955

ken.stricklett@nist.gov

Charles Hagwood

National Institute of Standards and Technology

100 Bureau Drive, MS-8980

Gaithersburg, MD 20899-8980

301-975-2846

charles.hagwood@nist.gov 


\section{Acknowledgments}

This report was completed with support from the U.S. Department of Energy and the Technology Administration of the U.S. Department of the Commerce.

\section{References}

[1] Energy conservation program: Test procedures for distribution transformers. Federal Register, in press, 2004.

[2] Energy conservation program: Test procedures for distribution transformers. Federal Register, 63(218):63359-63372, Thursday, November 12, 1998.

[3] Energy conservation program for consumer products. 10 Code of Federal Regulations Part 430, Chapter II, Office of the Federal Register, National Archives and Records Administration, Washington, DC, 1997. pp 93-263.

[4] K. L. Stricklett, M. Vangel, and O. Petersons. An analysis of efficiency testing under the Energy Policy and Conservation Act: A case study with application to distribution transformers. NIST Technial Note 1427, National Institute of Standards and Technology, Technology Administration, U.S. Department of Commerce, April 1999.

[5] Energy Policy and Conservation Act of 1975, Public Law 94-163, as amended by National Energy Conservation Policy Act of 1978, Public Law 95-619; National Appliance Energy Conservation Act of 1987, Public Law 100-12; National Appliance Energy Conservation Amendments of 1988, Public Law 100-357; and Section 122(d), Energy Policy Act of 1992, Public Law 102-486, October 24, 1992.

[6] United States Code, Title 42-The Public Health and Welfare, Chapter 77-Energy Conservation, Subchapter IIIImproving Energy Efficiency, Part A-1-Certain Industrial Equipment, 2000 Edition. United States Government Printing Office, Washington.

[7] NEMA Standards Publication TP 1-2002, Guide for determining energy efficiency for distribution transformers. National Electrical Manufacturers Association, Rosslyn, VA, 2002.

[8] NEMA Standards Publication TP 2-1998, Standard test method for measuring the energy comsumption of distribution transformers. National Electrical Manufacturers Association, Rosslyn, VA, 1998.

[9] C57.12.00-2000 IEEE Standard General requirements for liquid-immersed distribution, power and regulating transformers. Institute of Electrical and Electronics Engineers, New York, 2000.

[10] C57.12.01-1998 IEEE Standard General requirements for dry-type distribution and power transformers, including those with solid case and/or resin-encapsulated windings. Institute of Electrical and Electronics Engineers, New York, 1998.

[11] P. R. Bevington and D. K. Robinson. Data Reduction and Error Analysis for the Physical Sciences, chapter 5. McGrawHill, 1992.
[12] K. L. Stricklett and M. G. Vangel. Electric motor efficiency testing under the new part 431 of chapter II of title 10, Code of Federal Regulations: Enforcement testing. NIST Technical Note 1422, National Institute of Standards and Technology, Technology Administration, U.S. Department of Commerce, December 1996.

[13] K. L. Stricklett and M. G. Vangel. Analysis of proposals for compliance and enforcement testing under the new part 431; title 10, Code of Federal Regulations. NISTIR 6092, National Institute of Standards and Technology, Technology Administration, U.S. Department of Commerce, January 1998.

[14] M. G. Vangel. The joint distribution of a normal mean and extremum with applications to quality control. In Proceedings of the Section on Physical and Engineering Sciences. American Statistical Association, 1998.

[15] Public hearing on energy efficiency test procedures distribution transformers. U.S. Department of Energy, Wednesday, January 6, 1999. Transcript of the Public Hearing.

[16] Anthony Balducci. Comments on the Proposed Rule for Test Procedures for Distribution Transformers. U.S. Department of Energy, Docket No. EE-TP98-550, July 23, 1999. Letter submitted by the Transformer Section of the National Electrical Manufacturers Association (NEMA).

[17] Barry N. Taylor and Chris E. Kuyatt. Guidelines for evaluating and expressing the uncertainty of NIST measurement results. NIST Technial Note 1297, National Institute of Standards and Technology, Technology Administration, U.S. Department of Commerce, January 1993.

[18] P. J. Bickel and K. A. Doksum. Mathematical Statistics. Holden Day, Oakland, CA, 1977.

[19] R. S. Schulman. Statistics in Plain English with Computer Applications. Van Norstand Reinhold, New York, 1992.

[20] C. Stein. A two-sample test for a linear hypothesis whose power is independent of variance. Annals of Mathematical Statistics, 16:243-258, 1945. 


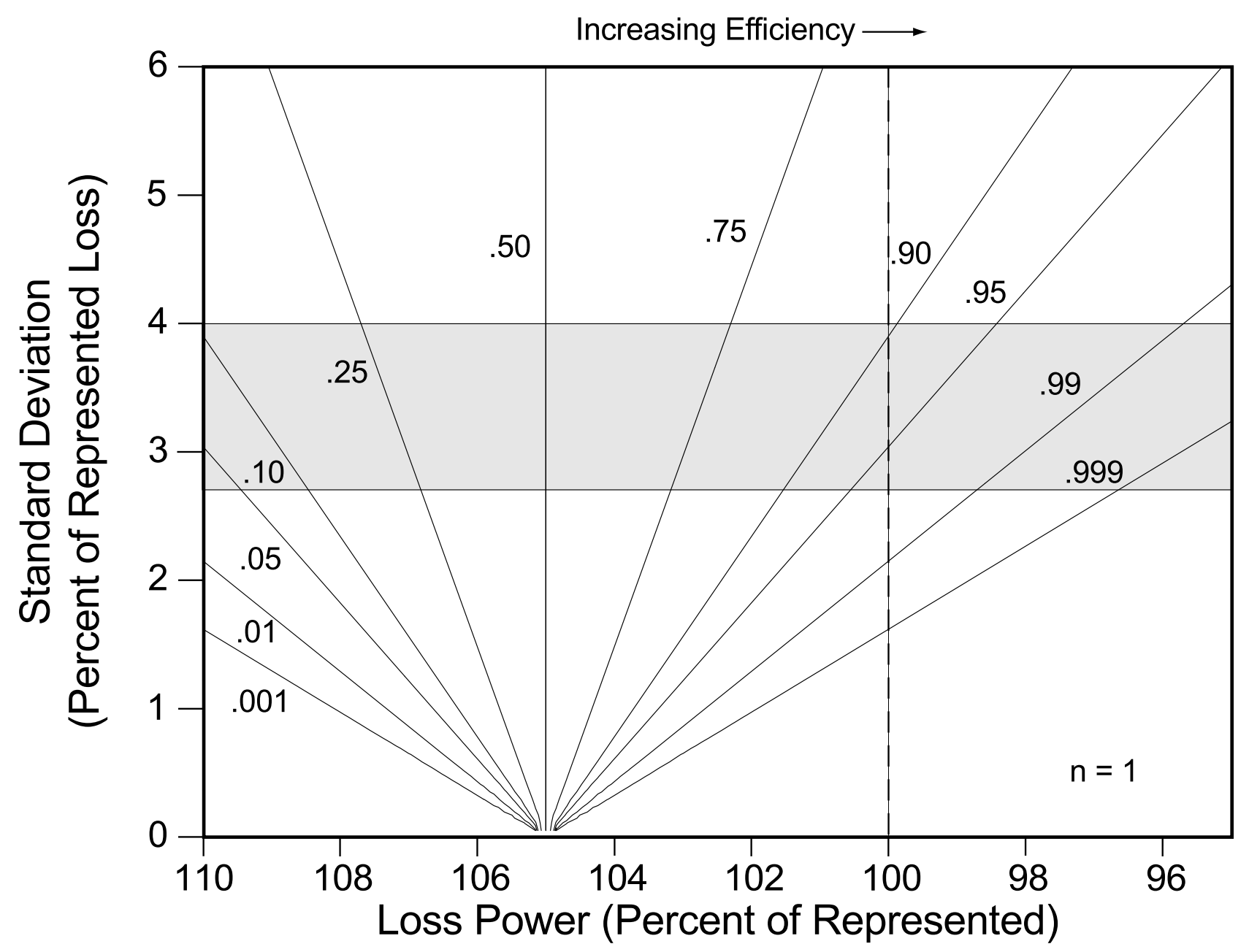

Figure 1: The operating characteristics of the sampling plan for compliance testing for an expanded uncertainty $(5 / \sqrt{n}) \%$ and a sample of one. The normalized loss of the basic model is indicated on the horizontal axis and the normalized standard deviation of the losses is indicated on the vertical axis. The contours indicate the probability of demonstrating compliance, e.g., the 0.90 contour corresponds to a $90 \%$ likelihood of demonstrating compliance. The represented loss is indicated by the vertical broken line at $100 \%$. The horizontal band from 2.7-4.0\% indicates the range of standard deviations likely to be encountered for distribution transformers. 


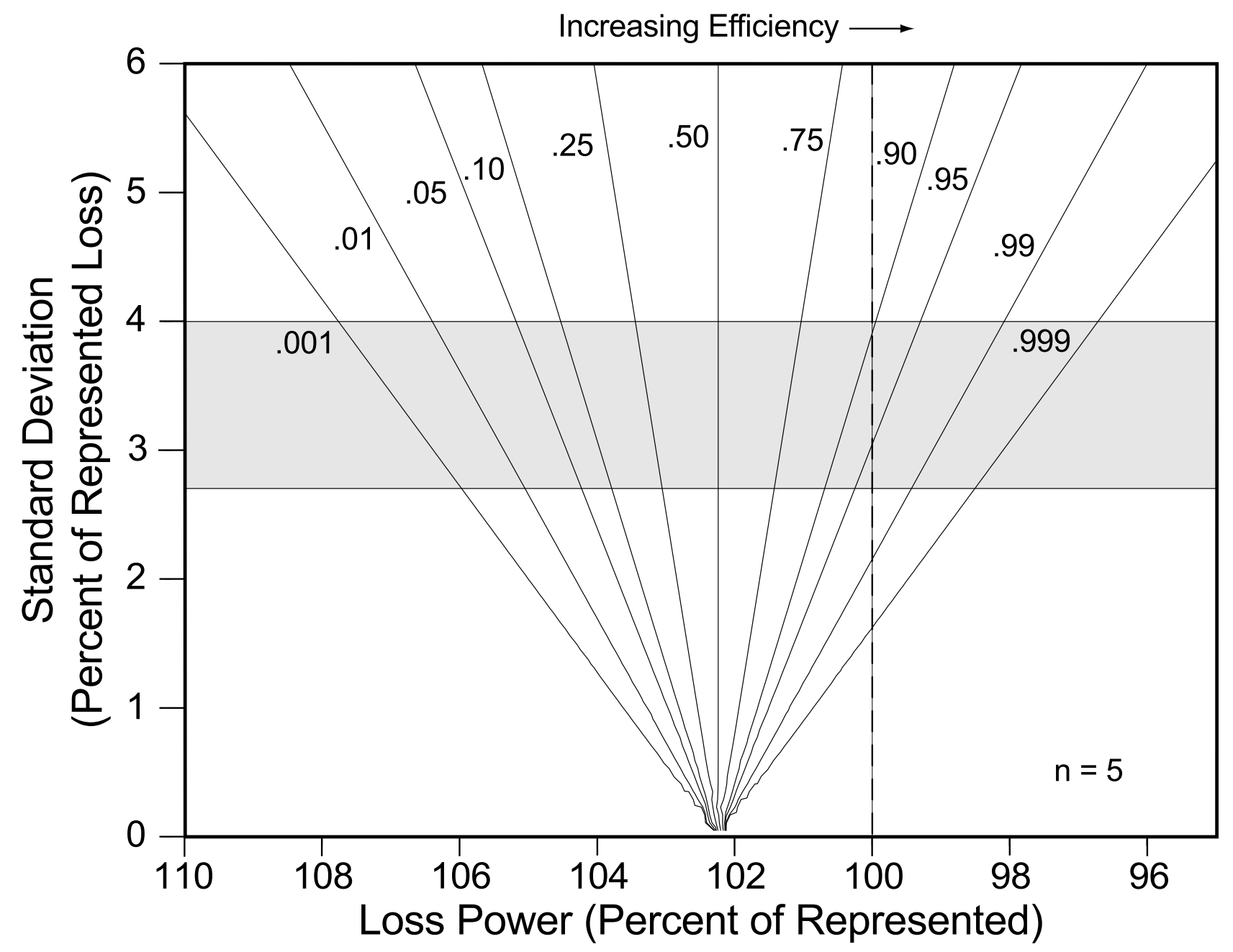

Figure 2: The operating characteristics of the sampling plan for compliance testing for an expanded uncertainty $(5 / \sqrt{n}) \%$ for a sample of $n=5$ units. The normalized loss of the basic model is indicated on the horizontal axis and the normalized standard deviation of the losses is indicated on the vertical axis. The contours indicate the probability of demonstrating compliance, e.g., the 0.90 contour corresponds to a $90 \%$ likelihood of demonstrating compliance. The represented loss is indicated by the vertical broken line at $100 \%$. The horizontal band from 2.7-4.0\% indicates the range of standard deviations likely to be encountered for distribution transformers. 


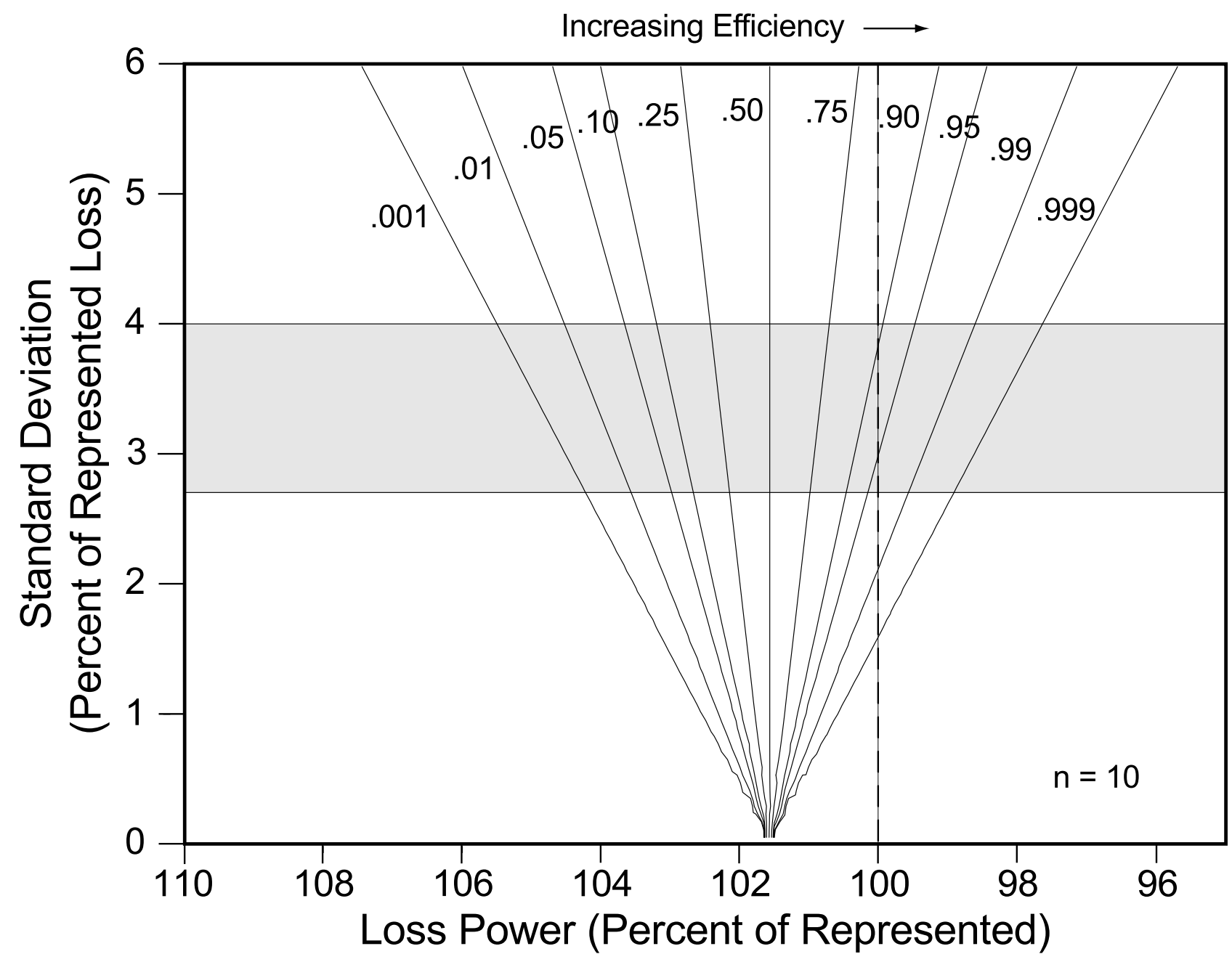

Figure 3: The operating characteristics of the sampling plan for compliance testing for an expanded uncertainty $(5 / \sqrt{n}) \%$ for a sample of $n=10$ units. The normalized loss of the basic model is indicated on the horizontal axis and the normalized standard deviation of the losses is indicated on the vertical axis. The contours indicate the probability of demonstrating compliance, e.g., the 0.90 contour corresponds to a $90 \%$ likelihood of demonstrating compliance. The represented loss is indicated by the vertical broken line at $100 \%$. The horizontal band from 2.7-4.0\% indicates the range of standard deviations likely to be encountered for distribution transformers. 


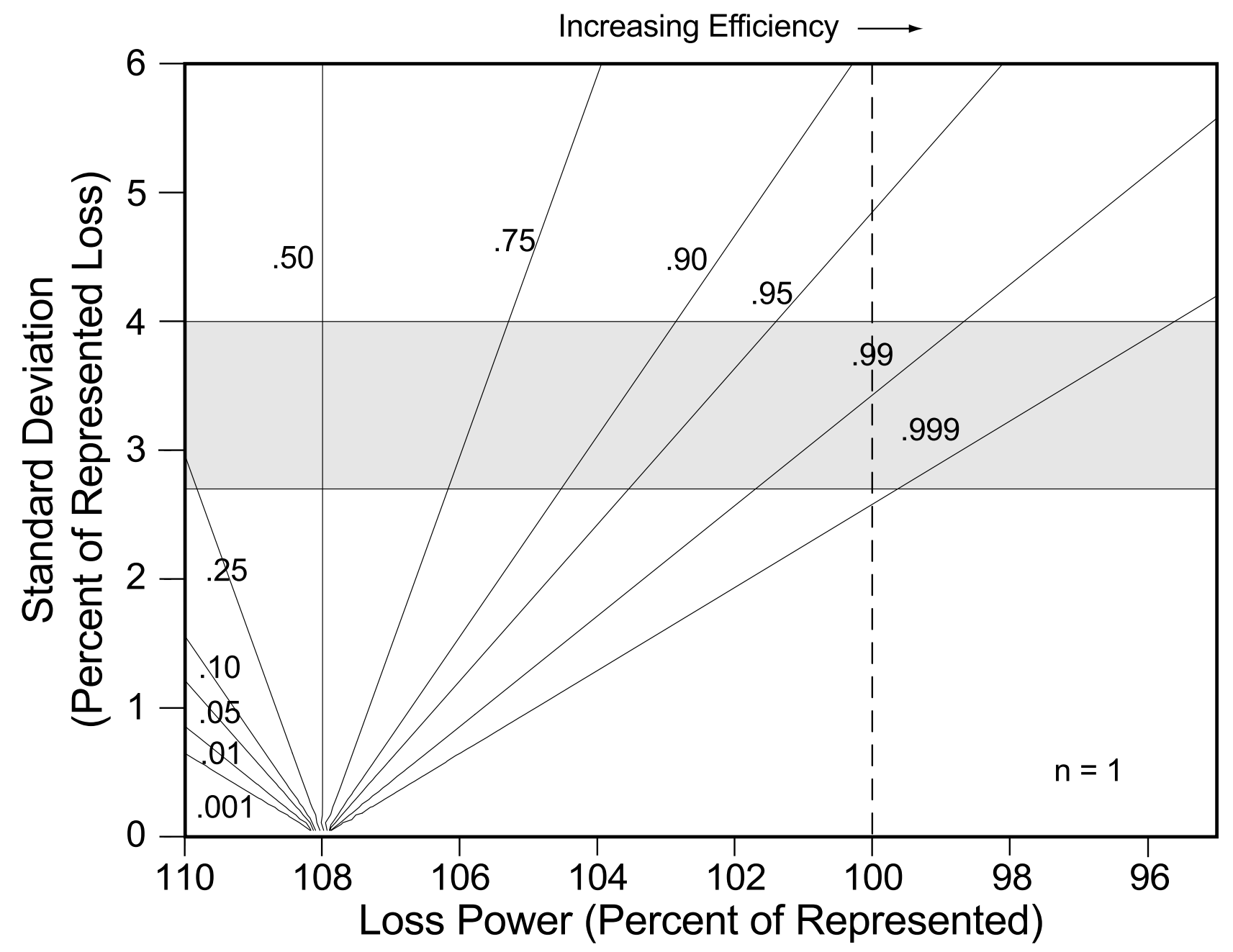

Figure 4: The operating characteristics of the sampling plan for compliance testing for an expanded uncertainty $(8 / \sqrt{n}) \%$ for a sample of $n=1$ units. The normalized loss of the basic model is indicated on the horizontal axis and the normalized standard deviation of the losses is indicated on the vertical axis. The contours indicate the probability of demonstrating compliance, e.g., the 0.90 contour corresponds to a $90 \%$ likelihood of demonstrating compliance. The represented loss is indicated by the vertical broken line at $100 \%$. The horizontal band from 2.7-4.0\% indicates the range of standard deviations likely to be encountered for distribution transformers. 


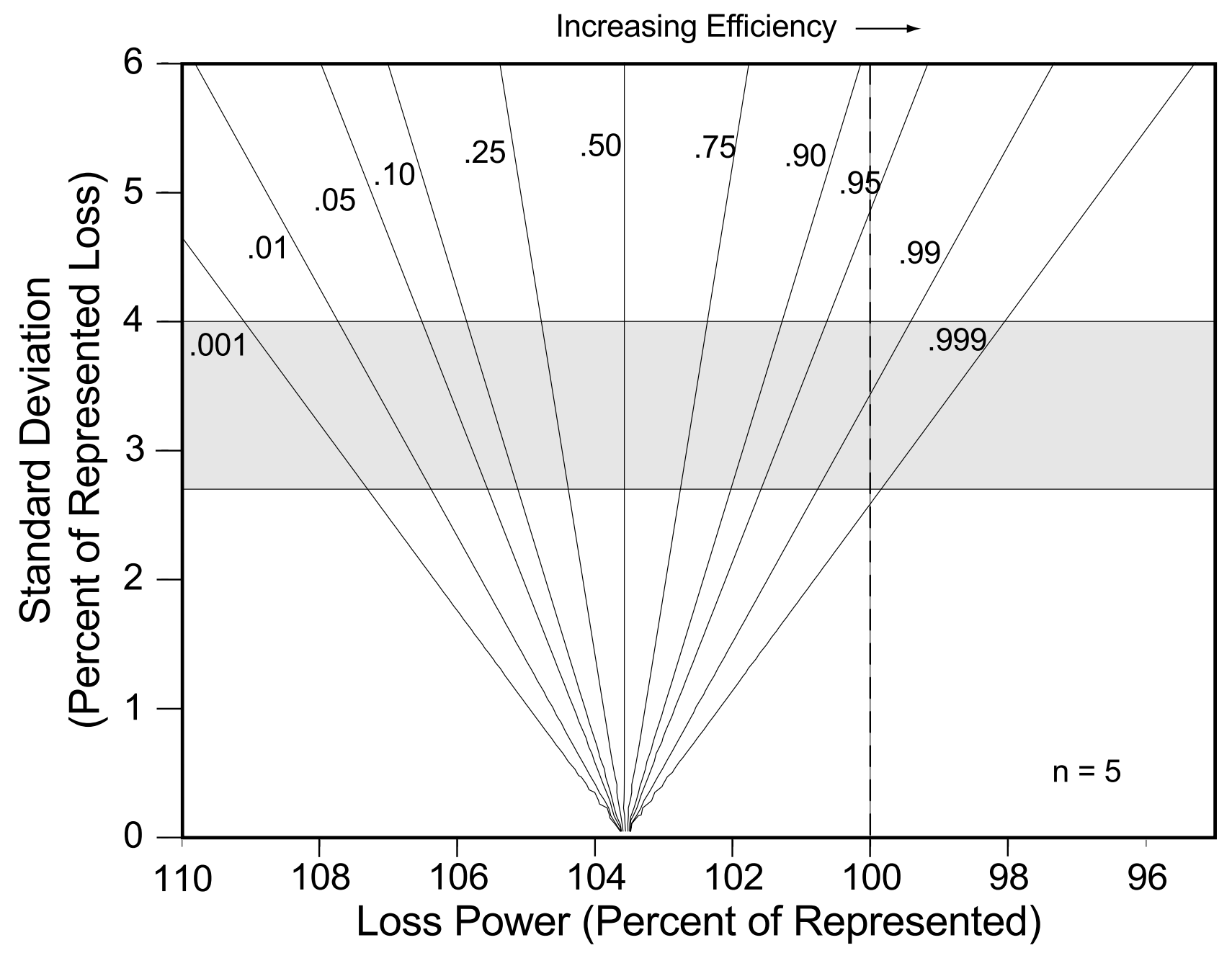

Figure 5: The operating characteristics of the sampling plan for compliance testing for an expanded uncertainty $(8 / \sqrt{n}) \%$ for a sample of $n=5$ units. The normalized loss of the basic model is indicated on the horizontal axis and the normalized standard deviation of the losses is indicated on the vertical axis. The contours indicate the probability of demonstrating compliance, e.g., the 0.90 contour corresponds to a $90 \%$ likelihood of demonstrating compliance. The represented loss is indicated by the vertical broken line at $100 \%$. The horizontal band from 2.7-4.0\% indicates the range of standard deviations likely to be encountered for distribution transformers. 


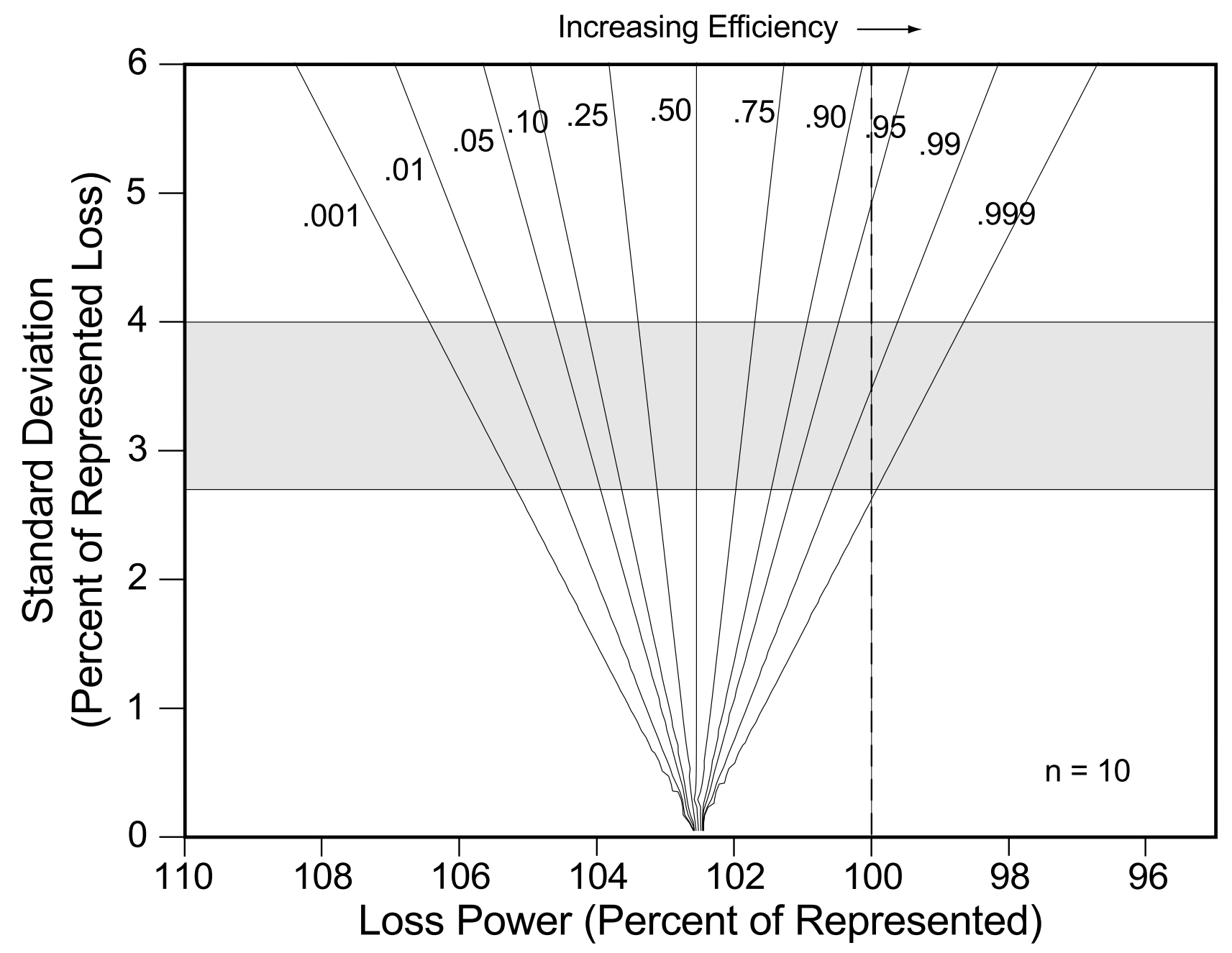

Figure 6: The operating characteristics of the sampling plan for compliance testing for an expanded uncertainty $(8 / \sqrt{n}) \%$ for a sample of $n=10$ units. The normalized loss of the basic model is indicated on the horizontal axis and the normalized standard deviation of the losses is indicated on the vertical axis. The contours indicate the probability of demonstrating compliance, e.g., the 0.90 contour corresponds to a $90 \%$ likelihood of demonstrating compliance. The represented loss is indicated by the vertical broken line at $100 \%$. The horizontal band from 2.7-4.0\% indicates the range of standard deviations likely to be encountered for distribution transformers. 


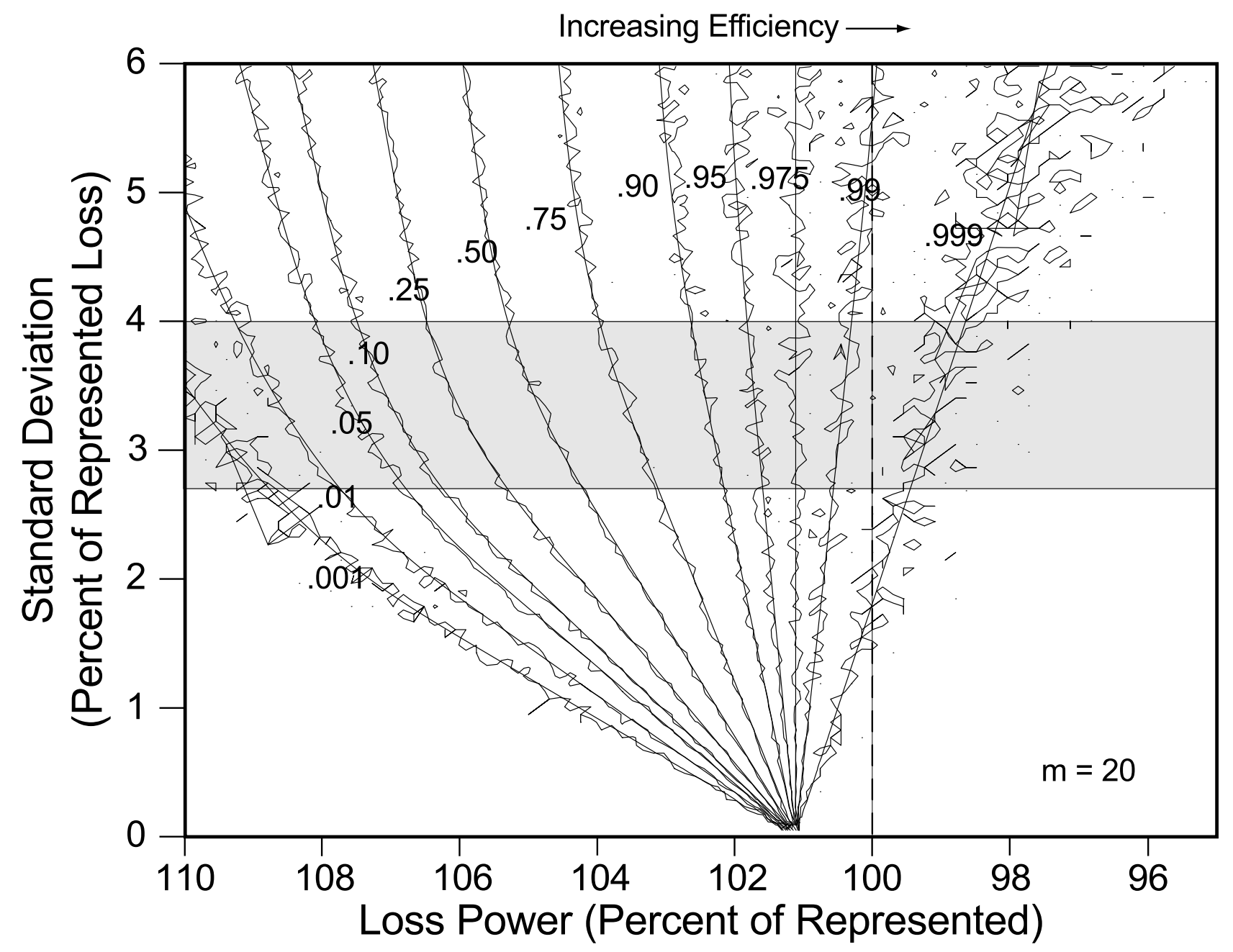

Figure 7: The operating characteristics of the Sampling Plan for Enforcement Testing for $m=20$. The normalized loss is indicated on the horizontal axis and the normalized standard deviation of the losses is indicated on the vertical axis. The contours indicate the probability of demonstrating compliance, e.g., the 0.90 contour corresponds to a $90 \%$ likelihood of demonstrating compliance. The represented loss is indicated by the vertical broken line at $100 \%$. The horizontal band from $2.7-4.0 \%$ indicates the range of standard deviations likely to be encountered for distribution transformers. 


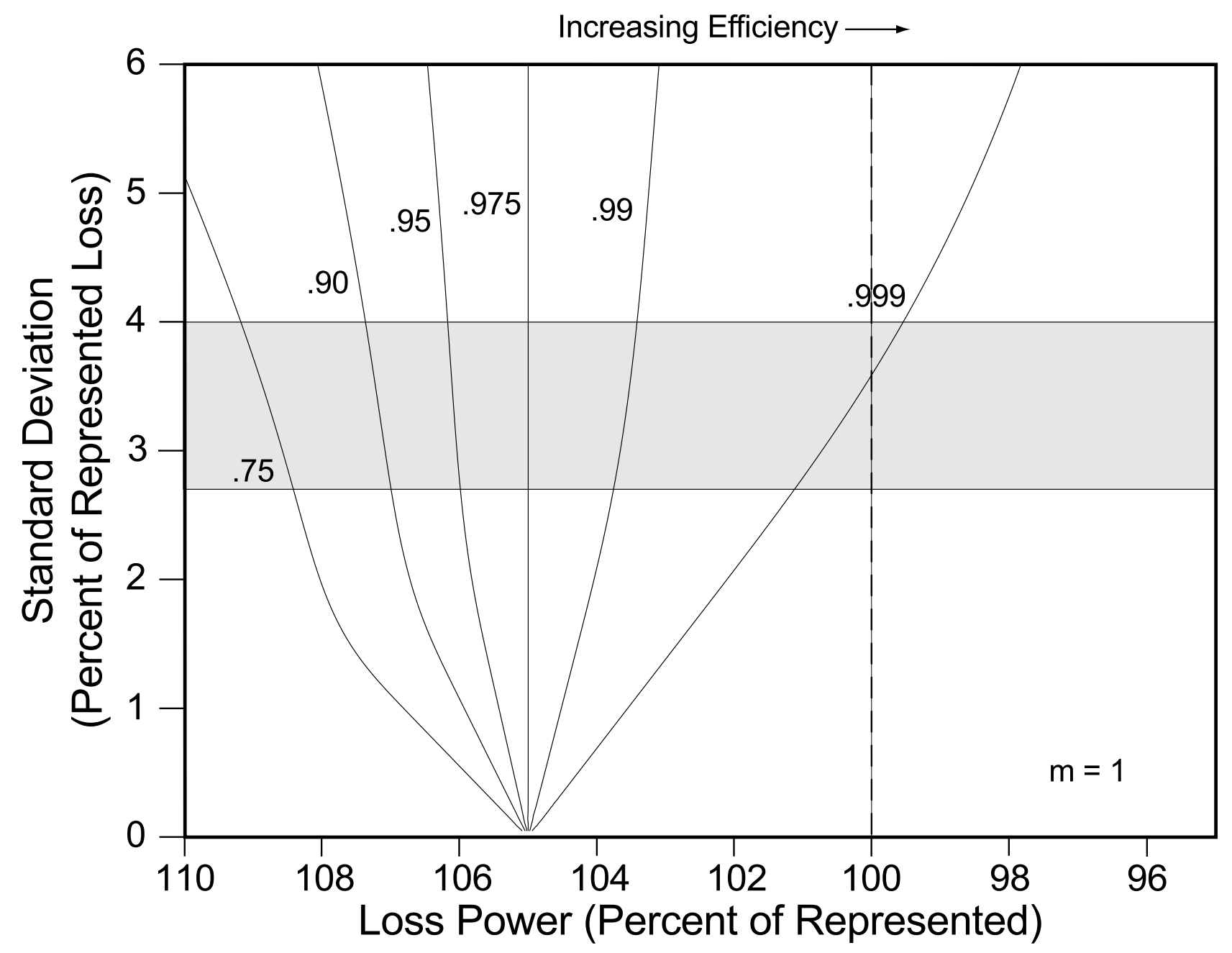

Figure 8: The operating characteristics of the Sampling Plan for Enforcement Testing for $m=1$. The normalized loss is indicated on the horizontal axis and the normalized standard deviation of the losses is indicated on the vertical axis. The contours indicate the probability of demonstrating compliance, e.g., the 0.90 contour corresponds to a $90 \%$ likelihood of demonstrating compliance. The represented loss is indicated by the vertical broken line at $100 \%$. The horizontal band from $2.7-4.0 \%$ indicates the range of standard deviations likely to be encountered for distribution transformers. 


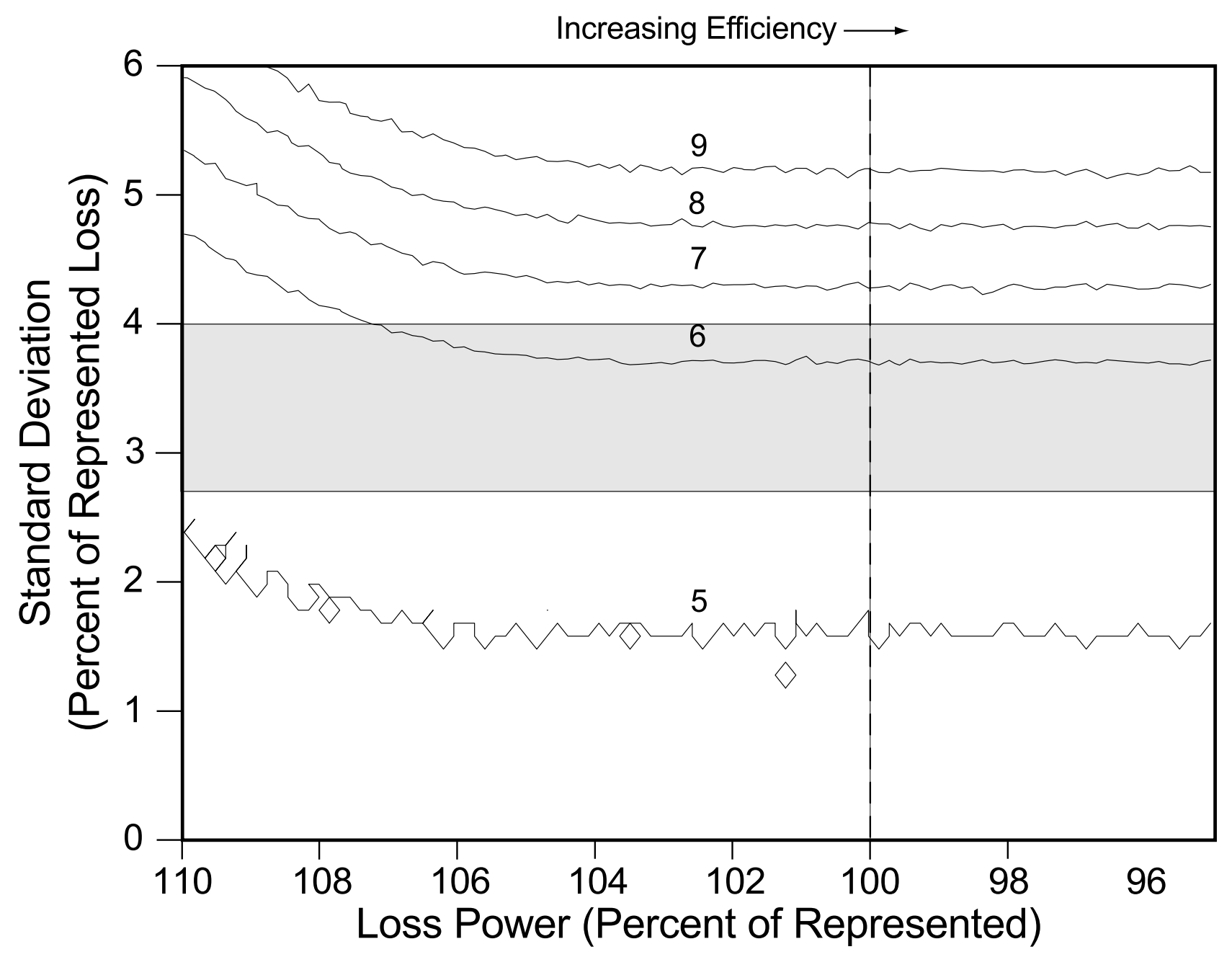

Figure 9: The average number of units tested under the Sampling Plan for Enforcement Testing. The normalized loss is indicated on the horizontal axis and the normalized standard deviation of the losses is indicated on the vertical axis. The contours indicate the average number of units tested, e.g., the 5 contour corresponds to 5 units tested. The represented loss is indicated by the vertical broken line at $100 \%$. The horizontal band from $2.7-4.0 \%$ indicates the range of standard deviations likely to be encountered for distribution transformers. 


\section{Appendix A}

\section{Compliance testing}

The sampling plan for compliance testing appears in $\S 432.12(b)(2)$ of the proposed 10 CFR Part 432:

(2) Selection of units for testing within a basic model. For each basic model a manufacturer selects for testing, it shall select a sample of units at random and test them. The sample shall be comprised of production units of the basic model, or units that are representative of such production units. The sample size shall be not fewer than five units, except that when the manufacturer would produce fewer than five units of a basic model over a reasonable period of time (approximately 180 days), then it must test each unit. However, a manufacturer may not use a basic model with a sample size of fewer than five units to substantiate or verify an AEDM pursuant to paragraphs (a)(3) or (a)(4) of this section. In a test of compliance with a represented efficiency:

The average efficiency of the sample, $\bar{X}$, which is defined by

$$
\bar{X}=\frac{1}{n} \sum_{i=1}^{n} X_{i}
$$

where $X_{i}$ is the measured efficiency of unit $i$ and $n$ is the number of units tested, shall satisfy the condition:

$$
\bar{X} \geq \frac{100}{1+\left(1+\frac{0.05}{\sqrt{n}}\right)\left(\frac{100}{R E}-1\right)}
$$

where $R E$ is the represented efficiency. 


\section{Appendix B}

\section{Substantiation of an AEDM}

The criteria for substantiation of an Alternative Efficiency Determination Method (AEDM) are provided in $\S 432.12(a)(3)$ of the proposed 10 CFR Part 432:

(3) Substantiation of an alternative efficiency determination method. Before using an AEDM, the manufacturer must substantiate the AEDM's accuracy and reliability as follows:

(i) Apply the AEDM to at least five of the manufacturer's basic models that have been selected for testing in accordance with paragraph (b)(1) of this section, and calculate the power loss for each of these basic models;

(ii) Test at least five units of each of these basic models in accordance with the applicable test procedure and paragraph (b)(2) of this section, and determine the power loss for each of these basic models;

(iii) The predicted total power loss for each of these basic models, calculated by applying the AEDM pursuant to paragraph (a)(3)(i) of this section, must be within plus or minus five percent of the mean total power loss determined from the testing of that basic model pursuant to paragraph (a)(3)(ii) of this section; and

(iv) Calculate for each of these basic models the percentage that its power loss calculated pursuant to paragraph (a)(3)(i) is of its power loss determined from testing pursuant to paragraph (a)(3)(ii), compute the average of these percentages, and that calculated average power loss, expressed as a percentage of the average power loss determined from testing, must be no less than 97 percent and no greater than 103 percent. 


\section{Appendix C}

\section{Enforcement testing}

Appendix B to Subpart B of Part 432—Sampling Plan for Enforcement Testing

Step 1. The number of units in the sample $\left(m_{1}\right)$ shall be in accordance with $\S \S 432.13(a)(4), 432.13(a)(5), 432.13(a)(6)$ and 432.13(a)(7) and shall not be greater than twenty. The number of tests in the first sample $\left(n_{1}\right)$ shall be in accordance with $\S 432.13(\mathrm{a})(8)$ and shall be not fewer than four.

Step 2. Compute the mean $\left(\bar{X}_{1}\right)$ of the measured energy performance of the $n_{1}$ tests in the first sample by using equation 1 as follows:

$$
\bar{X}_{1}=\frac{1}{n_{1}} \sum_{i=1}^{n_{1}} X_{i}
$$

where $X_{i}$ is the measured efficiency of test $i$.

Step 3. Compute the sample standard deviation $\left(S_{1}\right)$ of the measured efficiency of the $n_{1}$ tests in the first sample by using equation 2 as follows:

$$
S_{1}=\sqrt{\frac{\sum_{i=1}^{n_{1}}\left(X_{i}-\bar{X}_{1}\right)^{2}}{n_{1}-1}} .
$$

Step 4. Compute the standard error $\left(S E\left(\bar{X}_{1}\right)\right)$ of the mean efficiency of the first sample by using equation 3 as follows:

$$
S E\left(\bar{X}_{1}\right)=\frac{S_{1}}{\sqrt{n_{1}}}
$$

Step 5. Compute the sample size discount $\left(S S D\left(m_{1}\right)\right)$ by using equation 4 as follows:

$$
S S D\left(m_{1}\right)=\frac{100}{1+\left(1+\frac{.05}{\sqrt{m_{1}}}\right)\left(\frac{100}{R E}-1\right)}
$$

where $m_{1}$ is the number of units in the sample, and $R E$ is the applicable EPCA efficiency when the test is to determine compliance with the applicable statutory standard, or is the labeled efficiency when the test is to determine compliance with the labeled efficiency value.

Step 6. Compute the lower control limit $\left(L C L_{1}\right)$ for the mean of the first sample by using equation 5 as follows:

$$
L C L_{1}=S S D\left(m_{1}\right)-t S E\left(\bar{X}_{1}\right)
$$

where $t$ is the 2.5 percentile of a $t$-distribution for a sample size of $m_{1}$, which yields a 97.5 percent confidence level for a one-tailed $t$-test.

Step 7. Compare the mean of the first sample $\left(\bar{X}_{1}\right)$ with the lower control limit $\left(L C L_{1}\right)$ to determine one of the following:

(i) If the mean of the first sample is below the lower control limit, then the basic model is in non-compliance and testing is at an end.

(ii) If the mean is equal to or greater than the lower control limit, no final determination of compliance or non-compliance can be made; proceed to Step 8 . 
Step 8. Determine the recommended sample size $(n)$ by using equation 6 as follows:

$$
n=\left[\frac{t S_{1}(105-0.05 R E)}{R E(5-0.05 R E)}\right]^{2}
$$

where $S_{1}$ and $t$ have the values used in Steps 3 and 6, respectively. The factor

$$
\frac{105-0.05 R E}{R E(5-0.05 R E)}
$$

is based on a 5 percent tolerance in the total power loss.

Given the value of $n$, determine one of the following:

(i) If the value of $n$ is less than or equal to $n_{1}$ and if the mean energy efficiency of the first sample $\left(\bar{X}_{1}\right)$ is equal to or greater than the lower control limit $\left(L C L_{1}\right)$, the basic model is in compliance and testing is at an end.

(ii) If the value of $n$ is greater than $n_{1}$, and no additional units are available for testing, testing is at an end and the basic model is in non-compliance. If the value of $n$ is greater than $n_{1}$, and additional units are available for testing, select a second sample $n_{2}$. The size of a second sample $n_{2}$ is determined to be the smallest integer equal to or greater than the difference $n-n_{1}$. If the value of $n_{2}$ so calculated is greater than $20-n_{1}$, set $n_{2}$ equal to $20-n_{1}$.

Step 9. After testing the $n_{2}$ sample, compute the combined mean $\left(\bar{X}_{2}\right)$ of the measured energy performance of the $n_{1}$ and $n_{2}$ units of the combined first and second samples by using equation 7 as follows:

$$
\bar{X}_{2}=\frac{1}{n_{1}+n_{2}} \sum_{i=1}^{n_{1}+n_{2}} X_{i}
$$

Step 10. Compute the standard error $\left(S E\left(\bar{X}_{2}\right)\right)$ of the mean efficiency of the $n_{1}$ and $n_{2}$ tests in the combined first and second samples by using equation 8 as follows:

$$
S E\left(\bar{X}_{2}\right)=\frac{S_{1}}{\sqrt{n_{1}+n_{2}}} .
$$

(Note that $S_{1}$ is the value obtained above in Step 3.)

Step 11. Set the lower control limit $\left(L C L_{2}\right)$ to,

$$
L C L_{2}=S S D\left(m_{1}\right)-t S E\left(\bar{X}_{2}\right),
$$

where $t$ has the value obtained in Step 5 and $S S D\left(m_{1}\right)$ is sample size discount from Step 5. Compare the combined sample mean $\left(\bar{X}_{2}\right)$ to the lower control limit $\left(L C L_{2}\right)$ to find one of the following:

(i) If the mean of the combined sample $\left(\bar{X}_{2}\right)$ is less than the lower control limit $\left(L C L_{2}\right)$, the basic model is in non-compliance and testing is at an end.

(ii) If the mean of the combined sample $\left(\bar{X}_{2}\right)$ is equal to or greater than the lower control limit $\left(L C L_{2}\right)$, the basic model is in compliance and testing is at an end.

\section{MANUFACTURER-OPTION TESTING}

If a determination of non-compliance is made in Steps 6, 7 or 11, above, the manufacturer may request that additional testing be conducted, in accordance with the following procedures. 
Step A. The manufacturer requests that an additional number, $n_{3}$, of units be tested, with $n_{3}$ chosen such that $n_{1}+$ $n_{2}+n_{3}$ does not exceed 20 .

Step B. Compute the mean efficiency, standard error, and lower control limit of the new combined sample in accordance with the procedures prescribed in Steps 8, 9, and 10, above.

Step C. Compare the mean performance of the new combined sample to the lower control limit $\left(L C L_{2}\right)$ to determine one of the following:

(a) If the new combined sample mean is equal to or greater than the lower control limit, the basic model is in compliance and testing is at an end.

(b) If the new combined sample mean is less than the lower control limit and the value of $n_{1}+n_{2}+n_{3}$ is less than 20, the manufacturer may request that additional units be tested. The total of all units tested may not exceed 20. Steps A, B, and C are then repeated.

(c) Otherwise, the basic model is determined to be in non-compliance. 